\title{
FAKTOR INTERNAL SEBAGAI PENENTU NIAT MAHASISWA UNTUK BERWIRAUSAHA
}

\author{
Oey Hannes Widjaya ${ }^{1}$, Sanny Ekawati ${ }^{2}$ \\ ${ }^{1}$ Jurusan Ekonomi Manajemen, Universitas Tarumanagara Jakarta \\ Email: hannesw@fe.untar.ac.id \\ ${ }^{2}$ Jurusan Ekonomi Manajemen, Universitas Tarumanagara Jakarta \\ Email: sannye@fe.untar.ac.id
}

\begin{abstract}
ABSTRAK
Penelitian ini bertujuan untuk menjelaskan faktor-faktor penentu minat mahasiswa untuk berwirausaha. Dari kajian pustaka terdapat beberapa faktor internal yang menentukan minat mahasiswa untuk berwirausaha. Penelitian dilakukan pada beberapa perguruan tinggi swasta di Jakarta yang memiliki konsentrasi kewirausahaan. Sampel dipilih dengan menggunakan teknik purposive sampling yang terdapat di beberapa perguruan tinggi swasta pada mahasiswa fakultas ekonomi yang berkonsentrasi kewirausahaan. . Diteliti 300 mahasiswa fakultas ekonomi yang terdapat di 10 lokasi perguruan tinggi di Jakarta. Pengumpulan data diperoleh melaui kuesioner dengan menggunakan skala likert. Analisis dilakukan dengan menggunakan analisis faktor.

Hasil dari penelitian menunjukkan terdapat tiga faktor internal yang dominan bagi mahasiswa yang menentukan minat mahasiswa melakukan wirausaha. Dengan demikian hasil penelitian dapat memberikan kontribusi bagi perguruan tinggi khususnya mahasiswa untuk membekali mahasiswa meningkatkan pembelajaran mengenain kewirausahanan, sehingga diharapkan dapat menumbuhkan minat mahasiswa untuk berwirausaha.
\end{abstract}

Kata kunci: faktor internal. analisis faktor

\section{PENDAHULUAN}

\section{Latar Belakang}

Perkembangan dunia usaha dewasa ini semakin sempit ,tidak sebanding dengan pertumbuhan penduduk. Kondisi ini terlihat dari angka jumlah pengangguran terbuka di Indonesia telah mencapat 7,24 juta jiwa (BPS,2014.Untuk mengatasi hal tersebut. Hisrich \& Peter (2002), mengemukakan kewirausahaan merupakan proses menciptakan sesuatu yang baru dan mengambil segala risiko dan imbalannya. Berbagai faktor pendukung niat seseorang untuk berwirausaha. Chu, H., Benzing, C. \& McGee, C. (2007) menyatakan bahwa salah satu factor pendukung kewirausahaan di suatu Negara terletak pada motivasi dalam berwirausaha. Beberapa faktor telah ditemukan bahwa faktor yang memotivasi minat seseorang dalam berwirausaha adalah faktor internal (Kuratko, Hornsby, \& Nafziger, 2007). Stewart et al.(1998) juga menyatakan bahwa tumbuhnya . Faktor internal yang berasal dari dalam diri wirausahawan dapat berupa sifat-sifat personal, sikap, kemauan dan kemampuan individu yang dapat memberi kekuatan individu untuk berwirausaha.

Untuk mengembangkan semangat berwirausaha pada mahasiswa, hal yang perlu dilakukan adalah mengidentifikasi faktor-faktor yang mempengaruhi minat berwirausaha di kalangan mahasiswa. Berdasarkan kondisi inilah maka perlu diteliti lebih jauh tentang faktor-faktor penentu minat wirausaha mahasiswa di Jakarta.

\section{Rumusan Masalah}

Dengan fokus masalah yaitu: faktor internal apa saja menjadi penentu minat mahasiswa menjadi seorang wirausaha? Dan beberapa faktor internal tersebut, faktor apa yang paling dominan yang menjadi penentu untuk mengambil keputusan berwirausaha bagi mahasiswa?. Dengan tujuan untuk Mengkaji dan mengetahui faktor internal yang menentukan minat mahasiswa dalam berwirausaha. Mengkaji dan mengetahui faktor yang paling dominan yang menentukan mahawsiswa untuk berwirausaha 


\section{METODE PENELITIAN}

\section{Tahapan- Tahapan penelitian}

Penelitian ini terdiri 3 tahapan untuk mewujudkan tujuan akhir sebagai berikut:

1). Melakukan identifikasi, perguruan tinggi. Mata kuliah kewirausahaan, julah mahasiswa, jumlah kelas / mahasiswa yang mengikuti kuliah kewirausahaan menggunakan wawancara dan observasi lapangan.

2). Dari data yang diperoleh kemudian dilakukan pemilihan terhadap lokasi perguruan tinggi dengan cara: penarikan sampel pada mahasiswa kelas kewirausahaan

3). Fokus masalah menentukan faktor yang mempengaruhi minat berwirausaha bagi mahasiswa program S1 Fakultas Ekonomi, yang dipilih secara sampel di 10 Perguruan tinggi swasta di Jakarta.

Teknik pemilihan sampel dalam penelitian ini adalah purposive sampling. Purposive sampling adalah sampling di mana pengambilan elemen-elemen yang dimasukkan dalam sampel sesuai dengan kriteria yang telah ditentukan. Kriteria pengambilan sampel adalah tercatat sebagai mahasiswa yang sedang menempuh mata kuliah kewirausahaan, total sampel 300 mahasiswa.

Tabel 1. Faktor Indikator dan Pernyataan

\begin{tabular}{|c|c|c|c|}
\hline Faktor & Indikator & Pernyataan & Skala \\
\hline \multirow{3}{*}{$\begin{array}{l}\text { Faktor } \\
\text { Internal }\end{array}$} & $\begin{array}{l}\text { Kebutuhan } \\
\text { Akan } \\
\text { Prestasi }\end{array}$ & $\begin{array}{l}\text { - Melakukan yang paling baik pada tugas yang } \\
\text { sulit } \\
\text { - Berusaha kerja keras untuk memperbaiki } \\
\text { performa kerja sebelumnya } \\
\text { - Mencari tambahan tanggung jawab pada } \\
\text { pekerjaan yang diberikan } \\
\text { - Berusaha melakukan yang lebih baik }\end{array}$ & Likert \\
\hline & $\begin{array}{l}\text { Pengambilan } \\
\text { Resiko }\end{array}$ & $\begin{array}{l}\text { - } \quad \text { Menyukai tantangan } \\
\text { - } \quad \text { Mampu mengambil resiko } \\
\text { - } \quad \text { Mampu mengatasi persoalan } \\
\end{array}$ & Likert \\
\hline & Efikasi Diri & $\begin{array}{l}\text { - Memiliki keterampilan kepemimpinan yang } \\
\text { dibutuhkan untuk menjadi seorang wirausaha } \\
\text { - Memiliki kematangan mental untuk memulai } \\
\text { menjadi seorang wirausaha } \\
\text { - Memiliki kemampuan untuk menyelesaikan } \\
\text { pekerjaan dengan baik }\end{array}$ & Likert \\
\hline
\end{tabular}

Sumber: Nurul (2004), Lieli dan Hani (2011), Suryana (2003)

Teknik pengumpulan data yang digunakan adalah metode kuesioner tertutup. Dengan skla 1 sampai 7 ( Sangat tidak setuju sampai sangat setuju sekali) Data yang diperoleh adalah data primer. Selanjutnya Instrumen yang digunakan untuk memperoleh data dalam penelitian ini harus diuji validitas dan reliabilitasnya. Jika butir-butir pertanyaan / pernyataan mendapatkan hasil corrected item to total correlation minimal 0,2, menurut pendapat Aritonang (2007) maka butir-butir pertanyaan dinyatakan valid. Sugiyono, 2013 berpendapat butir-butir pertanyaan dikatakan reliabel jika menunjukkan alpa lebih besar atau sama dengan 0,6. 


\section{Teknik Analisis Data}

Yang digunakan dalam penelitian ini adalah analisis faktor, yaitu analisis yang pada prinsipnya digunakan untuk meringkas sejumlah variabel menjadi lebih sedikit dan menamakannya sebagai faktor.

Dalam melakukan analisis faktor ini, peneliti dibantu dengan program SPSS versi 20.00.

\section{HASIL DAN PEMBAHASAN}

\section{Uji Validitas dan Reliabilitas}

Pengujian validitas pada penelitian ini menggunakan pendekatan corrected item total correlation. Uji coba penentuan valid atau tidaknya setiap pertanyaan dilakukan dengan membandingkan nilai corrected item total correlation yang diperoleh melalui SPSS versi 20. Suatu instrumen dinyatakan valid apabila skor suatu butir dengan skor total minimal sebesar 0,2.

Tabel 2. Uji Validitas dan Reliabilitas Faktor Internal

\begin{tabular}{|c|c|c|c|}
\hline Indikator & Pernyataan & $\begin{array}{l}\text { Corrected } \\
\text { Item Total } \\
\text { Correlation }\end{array}$ & $\begin{array}{l}\text { Cronbach's } \\
\quad \text { Alpha }\end{array}$ \\
\hline \multirow{4}{*}{$\begin{array}{l}\text { Kebutuhan } \\
\text { Akan } \\
\text { Prestasi }\end{array}$} & $\begin{array}{l}\text { Melakukan yang paling baik pada tugas } \\
\text { yang sulit }\end{array}$ & 0,536 & \multirow{4}{*}{0,771} \\
\hline & $\begin{array}{lcr}\text { Berusaha kerja } & \text { keras } & \text { untuk } \\
\text { memperbaiki } & \text { performa } & \text { kerja } \\
\text { sebelumnya } & & \\
\end{array}$ & 0,657 & \\
\hline & $\begin{array}{l}\text { Mencari tambahan tanggung jawab pada } \\
\text { pekerjaan yang diberikan }\end{array}$ & 0,582 & \\
\hline & Berusaha melakukan yang lebih baik & 0,518 & \\
\hline \multirow{3}{*}{$\begin{array}{l}\text { Pengambila } \\
\text { n Resiko }\end{array}$} & Menyukai tantangan & 0,731 & \multirow{3}{*}{0,840} \\
\hline & Mampu mengambil resiko & 0,728 & \\
\hline & Mampu mengatasi persoalan & 0,658 & \\
\hline \multirow{3}{*}{ Efikasi Diri } & $\begin{array}{l}\text { Memiliki keterampilan kepemimpinan } \\
\text { yang dibutuhkan untuk menjadi seorang } \\
\text { wirausaha }\end{array}$ & 0,446 & \multirow{3}{*}{0,729} \\
\hline & $\begin{array}{l}\text { Memiliki kematangan mental untuk } \\
\text { memulai menjadi seorang wirausaha }\end{array}$ & 0,587 & \\
\hline & $\begin{array}{l}\text { Memiliki kemampuan untuk } \\
\text { menyelesaikan pekerjaan dengan baik }\end{array}$ & 0,640 & \\
\hline
\end{tabular}

Dari hasil uji validitas dan reliabilitas diketahui bahwa nilai Corrected Item Total Correlation untuk masing-masing pernyataan, lebih besar dari 0,2, sehingga dapat disimpulkan bahwa semua pernyataan adalah valid. Selanjutnya, hasil uji reliabilitas menggunakan Alpha Cronbach menunjukkan bahwa nilai Alpha Cronbach untuk setiap indikator lebih besar dari 0,6, sehingga dapat disimpulkan bahwa semua indikator adalah reliabel. 


\section{Deskripsi subyek penelitian}

Dalam deskripsi subyek penelitian ini akan diuraikan karakteristik respoden ditinjau dari jenis kelamin, usia, angkatan. Dari 300 mahasiswa/i di Jakarta yang diketahui bahwa responden yang memberikan penilaian dari kuesioner terdiri dari $45,7 \%$ laki-laki dan 54,3\% wanita dengan jumlah total responden 300 orang mahasiswa.Untuk usia, yang berusia 19 tahun sebanyak 20.3\%, yang berusia 20 tahun sebanyak 31.0\%, 21 tahun sebanyak 26,7\% dan 22 tahun sebanyak $22 \%$. Maka usia yang terbanyak 21 tahun. Dari angkatan perkuliahan, didapati bahwa jumlah responden yang kuliah angkatan 2011 sebanyak 38 orang (12,7\%), angkatan 2012 sebanyak 64 orang (21,3\%), angkatan 2013 sebanyak 86 orang (28,7\%), angkatan 2014 sebanyak 85 orang $(28,3 \%)$, dan angkatan 2015 sebanyak 27 orang (9\%).

\section{Deskripsi Obyek Penelitian}

Deskripsi obyek penelitian berisi tanggapan responden atas kelompok pernyataan pada factor internal sebagai penentu kinerja usaha ritel. Statistik deskriptif berfungsi untuk mengetahui tentang karakteristik sampel yang digunakan secara lebih rinci. Dengan menggunakan SPSS versi 20 statistik deskriptif menjabarkan mengenai jawaban responden dalam bentuk nilai rata-rata dan standar deviasi dari masing - masing faktor.

Tabel 3. Descriptive Statistics Perindikator Faktor Internal Descriptive Statistics

\begin{tabular}{|l|r|r|r|r|r|}
\hline & \multicolumn{1}{|c|}{$\mathrm{N}$} & Minimum & Maximum & Mean & Std. Deviation \\
\hline KAP1 & 300 & 3,00 & 7,00 & 5,6967 &, 87972 \\
\hline KAP2 & 300 & 3,00 & 7,00 & 5,7367 &, 90001 \\
\hline KAP3 & 300 & 3,00 & 7,00 & 5,8800 &, 91381 \\
\hline KAP4 & 300 & 3,00 & 7,00 & 5,7967 &, 87819 \\
\hline PR1 & 300 & 3,00 & 7,00 & 5,2867 & 1,00724 \\
\hline PR2 & 300 & 3,00 & 7,00 & 5,6667 &, 90828 \\
\hline PR3 & 300 & 3,00 & 7,00 & 5,5867 &, 95509 \\
\hline ED1 & 300 & 3,00 & 7,00 & 6,0333 &, 77947 \\
\hline ED2 & 300 & 3,00 & 7,00 & 6,1633 &, 65683 \\
\hline ED3 & 300 & 4,00 & 7,00 & 6,0533 &, 71099 \\
\hline Valid N (listwise) & 300 & & & & \\
\hline
\end{tabular}

KAP = Kebutuhan Akan Prestasi

PR = Pengambilan Resiko

ED $\quad=$ Efikasi Diri

Tabel tersebut menunjukkan bahwa terdapat 10 butir dari faktor internal, butir ke-9 (ED2 ). Menunjukkan rata-rata terbesar adalah 6,1633. Sedangkan rara rata yang paling kecil adalah butir 5 memiliki rata-rata 5.2867 .Dari segi penyeberan skor, butir 9 memiliki deviasi standar $(0,65683)$ yang paling kecil yang berarti paling baik. Sedangkan butir 5 sebesar $(1,00724)$ paling besar. Berarti memiliki akurasi pengukuran yang paling jelek.

\section{Faktor Yang Paling Dominan}

Langkah- langkah yang digunakan untuk menentukan faktor faktor yang palin dominan adalah:

a. Menilai Kelayakan Variabel 
Tabel 4. KMO and Bartlett's Test Faktor Internal

KMO and Bartlett's Test

\begin{tabular}{|c|c|}
\hline $\begin{array}{r}\text { Kaiser-Meyer-Olkin Measure of Sampling Adequacy. } \\
\text { Approx. Chi-Square }\end{array}$ & $\begin{array}{r}, 693 \\
951,634\end{array}$ \\
\hline Bartlett's Test of Sphericity & 45 \\
\hline Sig. &, 000 \\
\hline
\end{tabular}

Berdasarkan tabel di atas, maka dapat diketahui angka KMO untuk faktor internal sebesar 0,693 dan angka KMO untuk faktor eksternal sebesar 0,578, dengan tingkat Sig. 0,000. Karena angka KMO tersebut sudah diatas 0.5 dan tingkat signifikansi sudah berada di bawah 0.05 maka variabel dan sampel tersebut sudah layak dan dapat dilakukan analisis lebih lanjut. Hal tersebut juga membuktikan bahwa antar variabel terdapat korelasi.

b. Kriteria kelayakan MSA dilihat dari nilai Anti-image correlation pada table Antiimage matrices, dimana nilai MSA harus lebih besar dari 0.5. menunjukkan variabel diatas layak untuk diuji lebih lanjut.

c. Communalities adalah angka yang menyatakan jumlah varian setiap variabel yang dijelaskan oleh faktor dengan tujuan agar dapat diketahui seberapa besar varian yang dapat dijelaskan oleh faktor yang ada.

Berdasarkan KAP1 diperoleh nilai ekstraction sebesar 0,548. Ini berarti sekitar $54,8 \%$ varians dari variabel KAP1 dapat dijelaskan oleh faktor yang terbentuk dan demikian seterusnya untuk variabel lainnya. Ketentuan communalities adalah jika angkanya semakin besar, berarti variabel tersebut makin erat hubungannya dengan faktor yang terbentuk.

d. Menentukan berapa jumlah faktor yang layak. Analisis faktor umumnya akan mengusulkan jumlah faktor yang valid yang dapat mewakili variabel-variabel input. berdasarkan eigenvalue dan scree plot.

e. Rotated Component Matrix, Setelah diketahui bahwa untuk faktor internal tujuh faktor adalah jumlah yang optimal, maka langkah selanjutnya adalah mengetahui distribusi ke 10 faktor tersebut pada tiga faktor yang terbentuk. Caranya adalah dengan mendistribusikan beberapa faktor untuk dimasukkan ke dalam faktor mana dengan melihat tingkat korelasi masing-masing fakktor .

Nilai korelasi suatu variabel terhadap suatu faktor sudah menjadi lebih jelas. Jadi, variabel tersebut dapat berubah ke dalam faktor sesuai dengan nilai korelasinya terhadap faktor tersebut. Berikut penjelasan dalam bentuk tabel mengenai distribusi variabel ke dalam suatu faktor : 
Tabel 4. Distribusi Variabel Faktor Internal Kedalam Faktor

\begin{tabular}{|c|l|r|}
\hline Faktor & \multicolumn{1}{|c|}{ Variabel } & Faktor Loading \\
\hline \multirow{2}{*}{$\mathbf{1}$} & KAP1 & 0,736 \\
\cline { 2 - 3 } & KAP2 & $\mathbf{0 , 8 3 8}$ \\
\cline { 2 - 3 } & KAP3 & 0,775 \\
\cline { 2 - 3 } & KAP4 & 0,720 \\
\hline \multirow{2}{*}{$\mathbf{2}$} & PR1 & 0,887 \\
\cline { 2 - 3 } & PR2 & $\mathbf{0 , 8 8 8}$ \\
\cline { 2 - 3 } & PR3 & 0,833 \\
\hline \multirow{3}{*}{3} & ED1 & 0,709 \\
\cline { 2 - 3 } & ED2 & 0,839 \\
\cline { 2 - 3 } & ED3 & $\mathbf{0 , 8 7 2}$ \\
\hline
\end{tabular}

Jadi bila dilihat pada tabel di atas maka dapat diketahui bahwa ke-10 faktor pada penelitian ini telah direduksi menjadi 3 buah faktor.

1) Dari kolom component (1) diketahui korelasi yang paling tinggi adalah faktor KAP2 $(0,838)$.

2) Dari kolom component (2) diketahui korelasi yang paling tinggi adalah faktor PR2 $(0,888)$

3) Dari kolom component (3) diketahui korelasi yang paling tinggi adalah faktor ED3 $(0,872)$

Faktor Dominan pada Masing-Masing Universitas

Untuk mengetahui faktor-faktor yang dominan berpengaruh pada mahasiswa di masing-masing universitas, maka dilakukan uji perbandingan nilai antara masing-masing universitas terhadap faktor-faktor yang memengaruhi minat berwirausaha. Berikut adalah hasil perhitungan menggunakan SPSS:

Tabel 5.1. Dominasi Faktor-Faktor Yang Mempengaruhi Minat Berwirausaha

\begin{tabular}{|l|c|c|c|c|c|c|c|c|c|c|}
\hline \multirow{2}{*}{ UNIV } & \multicolumn{10}{|c|}{ Internal } \\
\cline { 2 - 11 }$y$ & KAP1 & KAP2 & KAP3 & KAP4 & PR1 & PR2 & PR3 & ED1 & ED2 & ED3 \\
\hline 1 & 5,6667 & 5,7000 & 5,9667 & 5,8000 & 5,3000 & 5,6667 & 5,7000 & 6,1000 & 6,1333 & 6,0333 \\
\hline 2 & 5,5333 & 5,5000 & 5,7333 & 5,5000 & 5,1000 & 5,6667 & 5,5667 & 5,9667 & 6,0333 & 5,8667 \\
\hline 3 & 5,5667 & 5,6333 & 5,9000 & 6,0333 & 5,2667 & 5,3667 & 5,4000 & 6,0667 & 6,1333 & 6,1000 \\
\hline 4 & 5,9000 & 6,0000 & 6,0667 & 6,1000 & 5,1667 & 5,6000 & 5,5667 & 5,7000 & 5,9000 & 6,0000 \\
\hline 5 & 5,7667 & 6,1000 & 5,9667 & 6,0000 & 5,6000 & 5,9333 & 5,8333 & 6,0667 & 6,1333 & 6,1000 \\
\hline 6 & 5,9000 & 5,6667 & 5,8000 & 5,6333 & 5,4667 & 5,9000 & 5,7667 & 6,0333 & 6,3333 & 6,0333 \\
\hline 7 & 5,7000 & 5,9000 & 6,0333 & 5,7667 & 5,1333 & 5,5667 & 5,3667 & 6,3667 & 6,5333 & 6,4000 \\
\hline 8 & 5,5333 & 5,4667 & 5,6667 & 5,5333 & 5,1333 & 5,5667 & 5,5000 & 5,9333 & 6,0333 & 5,8667 \\
\hline 9 & 5,5667 & 5,6000 & 5,8667 & 5,8000 & 5,3333 & 5,5000 & 5,3667 & 6,0333 & 6,2000 & 6,1667 \\
\hline 10 & 5,8333 & 5,8000 & 5,8000 & 5,8000 & 5,3667 & 5,9000 & 5,8000 & 6,0667 & 6,2000 & 5,9667 \\
\hline
\end{tabular}


Studi mengenai kewirausahaan merupakan studi yang sangat penting dan menarik. Menurut Hisrich \& Peter (2002), kewirausahaan merupakan proses menciptakan sesuatu yang baru dan mengambil segala risiko dan imbalannya sedangkan wirausaha adalah seorang innovator yaitu seseorang yang mengembangkan sesuatu yang unik dan berbeda. Untuk mengembangkan sesuatu yang unik terbut memerlukan motivasi dan minat yang kuat pada diri seseotrang, disamping membutuhkan media pembelajaran di perguruan tinggi. Chu, H., Benzing, C. \& McGee, C. (2007) menciptakan sesuatu yang baru dan mengambil segala risiko dan imbalannya sedangkan wirausaha adalah seorang inovator yaitu seseorang yang mengembangkan sesuatu yang unik dan berbeda. Untuk mengembangkan sesuatu yang unik tersebut memerlukan motivasi dan minat yang kuat pada diri seseorang, disamping membutuhkan media pembelajaran di perguruan tinggi. Chu, H., Benzing, C. \& McGee, C. (2007) menyatakan bahwa salah satu faktor pendukung kewirausahaan di suatu Negara terletak pada motivasi dalam berwirausaha. Studi mengenai kewirausahaan berarti studi yang membahas faktor-faktor yang membentuk manusia yang memiliki sifat tersebut. Tidak mudah membentuk manusia untuk memiliki sifat kewirausahaan karena tiap orang memiliki karakteristik yang berbeda.

Untuk mengembangkan semangat berwirausaha pada mahasiswa, hal yang perlu dilakukan adalah mengidentifikasi faktor-faktor yang memengaruhi minat berwirausaha di kalangan mahasiswa. Berdasarkan hasil penelitian yang dilakukan teridentifikasi tiga faktor yang dominan.

\section{KESIMPULAN DAN SARAN}

\section{Kesimpulan}

Berdasarkan analisis yang dilakukan maka dapat disimpulkan beberapa hal berikut:

1. Untuk faktor internal faktor yang paling dominan terdapat pada:

a. Dari kolom component (1) diketahui korelasi yang paling tinggi adalah faktor KAP2 $(0,838)$, yaitu: Berusaha kerja keras untuk memperbaiki performa kerja sebelumnya.

b. Dari kolom component (2) diketahui korelasi yang paling tinggi adalah faktor PR2 $(0,888)$, yaitu: Mampu mengambil risiko.

c. Dari kolom component (3) diketahui korelasi yang paling tinggi adalah faktor ED3 $(0,872)$, yaitu: Memiliki kemampuan untuk menyelesaikan pekerjaan dengan baik.

2. Dari hasil analisis faktor per Universitas menunjukkna faktor yang paling dominan adalah:

Universitas 1

Faktor Internal yang paling dominan memengaruhi mahasiswa untuk mengambil keputusan berwirausaha adalah ED2 (Memiliki kematangan mental untuk memulai menjadi seorang wirausaha).

Universitas 2

Faktor Internal yang paling dominan memengaruhi mahasiswa untuk mengambil keputusan berwirausaha adalah ED2 (Memiliki kematangan mental untuk memulai menjadi seorang wirausaha).

Universitas 3

Faktor Internal yang paling dominan memengaruhi mahasiswa untuk mengambil keputusan berwirausaha adalah ED2 (Memiliki kematangan mental untuk memulai menjadi seorang wirausaha).

Universitas 4

Faktor Internal yang paling dominan memengaruhi mahasiswa untuk mengambil keputusan berwirausaha adalah KAP4 (Berusaha melakukan yang lebih baik). 


\section{Universitas 5}

Faktor Internal yang paling dominan memengaruhi mahasiswa untuk mengambil keputusan berwirausaha adalah ED2 (Memiliki kematangan mental untuk memulai menjadi seorang wirausaha).

Universitas 6

Faktor Internal yang paling dominan mempengaruhi mahasiswa untuk mengambil keputusan berwirausaha adalah ED2 (Memiliki kematangan mental untuk memulai menjadi seorang wirausaha).

Universitas 7

Faktor Internal yang paling dominan memengaruhi mahasiswa untuk mengambil keputusan berwirausaha adalah ED2 (Memiliki kematangan mental untuk memulai menjadi seorang wirausaha).

Universitas 8

Faktor Internal yang paling dominan memengaruhi mahasiswa untuk mengambil keputusan berwirausaha adalah ED2 (Memiliki kematangan mental untuk memulai menjadi seorang wirausaha).

Universitas 9

Faktor Internal yang paling dominan memengaruhi mahasiswa untuk mengambil keputusan berwirausaha adalah ED2 (Memiliki kematangan mental untuk memulai menjadi seorang wirausaha).

Universitas 10

Faktor Internal yang paling dominan memengaruhi mahasiswa untuk mengambil keputusan berwirausaha adalah ED2 (Memiliki kematangan mental untuk memulai menjadi seorang wirausaha)..

\section{Saran}

a. Terdapat beberapa faktor yang menentukan minat berwirausaha, untuk itu perlu meningkatkan minat berwirausaha mahasiswa melalui faktor-faktor tersebut.

b. Penelitian ini dapat dijadikan sebagai referensi untuk penelitian lanjutan dengan melihat keterkaitan antar faktor tersebut dalam meningkatkan minat berwirausaha.

c. Penelitian juga dapat dilanjutkan dengan mengkaitkan faktor-faktor tersebut dalam memengaruhi minat berwirausaha mahasiswa.

Ucapan Terima Kasih (Acknowledgement)

Terimakasih kepada Kemenristekdikti yang telah mempercayakan Kami mengikuti penelitian dosen pemula. Juga kepada direktur dan staff DPPM Universitas Tarumanagara yang telah memberikan support atas terselesainya penelitian ini.

\section{REFERENSI}

Aritonang R. Lerbin R. (2007). Metode Penelitian Pemasaran. Jakarta: Ghalia Indonesia. BPS (2014), Tingkat Pengangguran Terbuka (TPT) Menurut Provinsi, 1986 - 2015

Chu, H., Benzing, C. \& McGee, C. (2007). Ghanaian and Kenyan Entrepreneurs : $\quad a$ comparative analysis of their motivatons, succsess characteristic and problems. Journal of Developmental Entrepreneurship.

Gerry. (2008). Tracking Student Entrepreneurial Potensial: Personal Attributes and the Propensity for Business Start-Ups after Graduation in a Portuguese University, International Research Journal Problems and Perspectives in Management. Volume:6.

Kuratko, Donald F. \& Hodgetts, Richard M. (2007). Entrepreneurship: Theory, Process, Practise.7th ed. (South - Western/Thomson publisher). 
Nishanta, B.(2008). Influence of Personality Traits and Socio-demograhpic Background of Undergraduate Student on Motivation for Entrepreneurial Career : The Case of Srilanka. Paper was presented at the Euro-Asia Management Studies Association (EAMSA) Conference, Japan.

Nurul. (2004). Entrepreneurial Intention among Indonesian and Norwegian Students. Journal of Enterprising Culture. Volume:21.

Priyanto, S. H. (2008) Di dalam Jiwa ada Jiwa: The Backbone and the Socil Contruction of Entrepreneurship. Pidato Pengukuhan Guru Besar Universitas Kristen Satya Wacana.

Sugiyono, 2013. Metode Penelitian Pendidikan, Pendekatan Kuantitatif, Kualitatif dan R\&D. Bandung: Alfabeta.

Suryana. (2003). Kewirausahaan, Pedoman Praktis, Kiat dan Proses Menunju Sukses, Edisi Revisi, Jakarta: Salemba Empat 